\title{
HÅP ER DRIVKRAFTEN
}

Rehalbilitering. Artikkelen tar for seg forskjellige perspektiver på rehabiliteringssykepleie og viser hvordan pasientens behov for sykepleie kan sikres i tverrfaglig samarbeid.

DOI-NUMMER:

\section{6) $\begin{aligned} & \text { denne studien ønsket } \\ & \text { vi å komme fram til } \\ & \text { en enkel tilnærming }\end{aligned}$} til tverrfaglig reha-

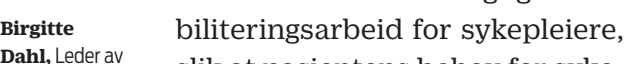
pleie pleie kan sikres itverrfaglig sammodell som viser hvordan sykepleieperspektiver i rehabilitering forholder seg til komponentene 1 Verdens helseorganisasjons inter sion funksionshemning og helse (ICF), som er helsemyndighetenes anbefalte modell for alle faggrupper i rehabiliteringsfeltet.

REHABLITERING. Rehabilitering brukes om tjenester for å bedre ter for unge, voksne og eldre med funksjonsproblemer. For barn brukes ordet habilitering. Tverrfaglighet
irehabiliteringsarbeidet er bestemt irehabiliteringsarbeidet er bestemt
i Forskrift om habilitering og rehabilitering individuell phngogrehabitor (1), der det sies at habilitering og rehabilitering er «tidsavgrensete, planlagte prosesser med klare mál og virkemidler, hvor flere aktorer samarbeider om à gn nodvendig bistand nå best mulig funksjons- og mestringsevne, selvstendighet og deltakelse sosialt og i samfunnet, Sykepleie er ofte grunnleggende for

kan sykepleiere ha vanskeligheter med à beskrive sin rolle og sine oppgaver itverrfaglig rehabiliteringsarfor sykepleiernes virksombet năr det gielder ICF, som utgior en felles modell for ulike faggruppers arbeid i re-

att problemer faget derimot, blir helse beletet som en prosess $(8,9)$. Sykepleiere bygger gjerne sin forståelse pả fenomener utgătt fra eksistensielle erfaringer, problemstillinger tipasset slike erfaringer, og sis (10,11). Dette perspektivet blit ikke vektlagt i ICF. Likevel bør sykepleiere i tverrfaglig rehabiliteringsarbeid kunne basere sine tilnærminger pã ICF, pả linje med vendig for å sikre at pasienten få̀r den sykepleie vedkommende har behov for i det tverrfaglige samarbeidet. Økt oppmerksomhet pa sosiale, politiske og kulturelle dmensjoner ved funksjonshemICF til et godt redskap for å utukle sykepleietenkning og praksis (5). I denne studien ville vi undersøke hvordan rehabiliteringssyke
STUDIE:

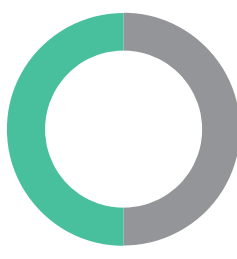
erspektiver i rehabilitering op mot ICF-modellen.

SYKEPLEIEPERSPEKTIVER ensikten med studien var å belyne oppgaver og ansvarsområder ehabilitering. Hovedmålet var â undersøke hvilke perspektiver sy telerne hadde irehabiliteringsmråder for sykepleieit revan ner overfor rehabiliteringspasienter. Il løpet av arbeidet så vi at sykedentifisert, kunne være aktuell modellen. Studiens neste målsetting ble derfor å vurdere om sykeleieperspektivene kunn relateres til ICF.

SPøRRESKJEMA OG INTERJUER. Det ble utviklet et spøder sykepleierne skulle beskrive sine ansvarsområder. Skjemae ble sendt til 100 medlemmer av aggruppe i rehabilitering i Norst Sysepleiefrorbund. Det kom in belt antall i en kvalitativ spørreskjema (12). I tillegg ble det gjort kvalitative intervjuer med fire erfarne kliniske spesialiste

habiliteringssykepleie.

\section{Fakta Hovec- budskap Artikkelen identifiserer
seks perspektiver på sy- kepleie i rehabiliterin og viser huordan disse
relatereres seg till CF-mo- relaterer seg till C-m-mo-
dellen, som er WHOs verktoy for tverrfagls
rehabiliteringsarbeid. Sykeplieperspektivene
setti fornold till CF kan for rehabiliteringssyke- pleie, som kan hielpe liggiore oppgavene of strukturerere arbeidet sit \\ Nølkkelord Les mer og finn littera- nettsider. - Rehabilitering - Habilitering
- Tverfaglighet
- Sykepleie}

Helsetilstand

(sykdom eller lidese)

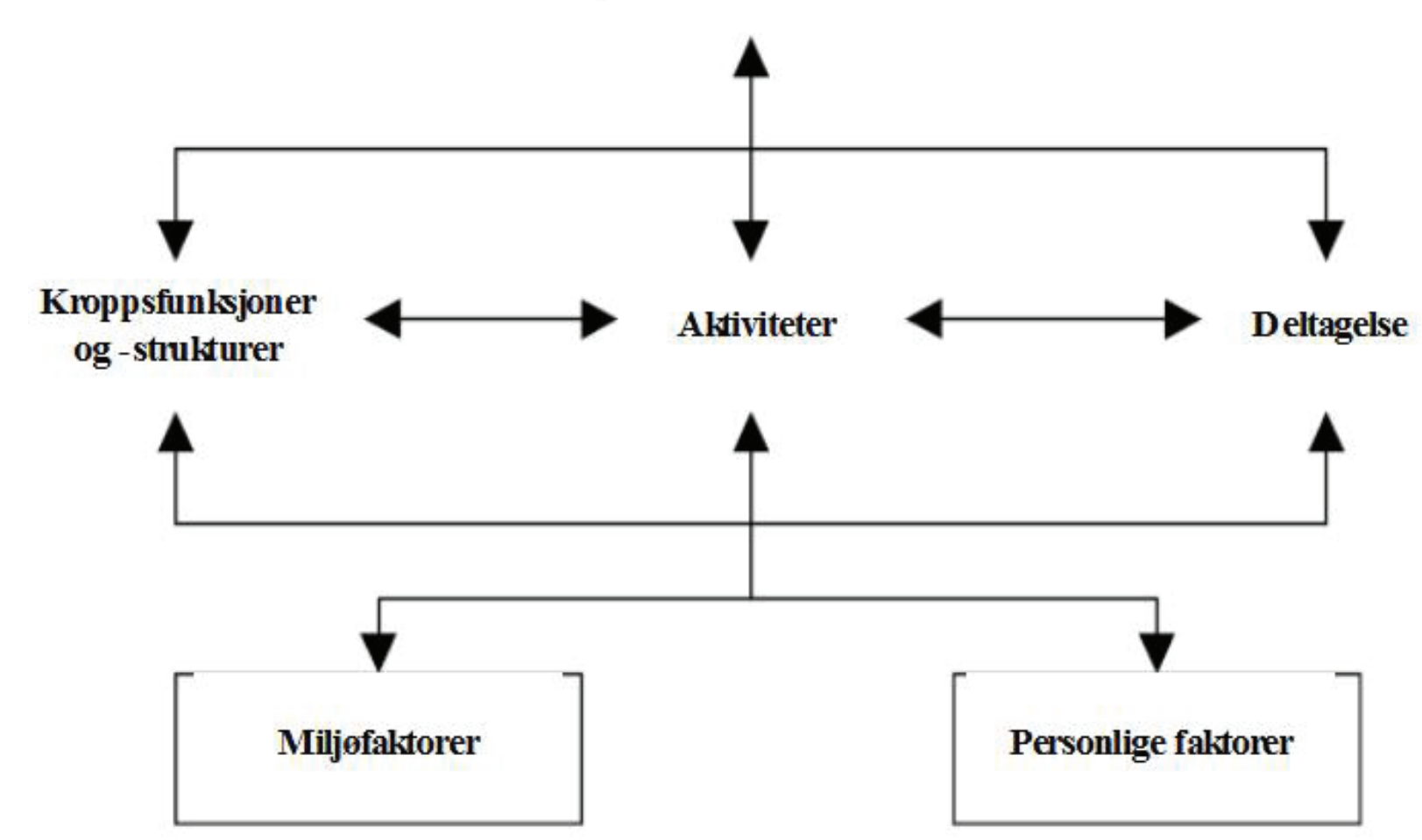

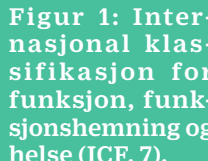

ETIKK. Studien ble godkjent av personvernombudet for forskning. Informantene fikk muntlig og skriftlig informasjon om studiens hensikt, at deltakelse var frivilig og at Sykepleierne som deltok i interviu er signerte en samtykkeerklæring.

PERSPEKTIVER. Sykepleiernes beskrivelser kunne samles i seks teo perspekttiv et brukerperspektivivet doseringsperspektiv, et mestringsperspektiv, et omgivelsesperspektiv og et oversiktsperspektiv. Perspektivene ble forankreti persondomenet, helse- og sykdomsdomenet og symptomhåndteringsmodell (SMM) (13). Denne modellen ble valgt fordi SMM's tre domener tilsvarer omráder som utgiør grunnlaget for begreering (14).
Tilsvarende områder ligger til grunn for ICF-modellen (7).

RELASJONSPERSPEKTIVET. Relsjonsperspektivet er forankret i perehabiliteringssykepleiens relasionelle grunnlag. Felgende faktorer underlagt relasjonsperspektivet: Relasjonen mellom sykepleieren og pasient//ruker

Relasionentil familien/nærstående Relasjonsperspektivet handle m sykepleiernes forhold til enkeltpersoner og grupper. En sykepleier esskrev hvordan hun la vekt på hyp-

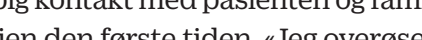
dem med omsorg, forklarte hun. Pasientene må forstå at mine hensikter er gode og at jeg vil deres be te. Det måjeg vise i praksis, ikke ba stille krav.» Krav till rehabiliteringspasienten er nødvendig for ả oppnà

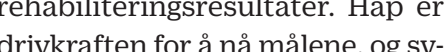
tepleerne har en spesill ongy

\section{«Jeg overøser}

dem med

omsorg."

med å bidra til pasientens og familens håp for fremtiden. Både pasient og nærståande moter utfordringer 1 teres best med fagfollk de foler seg ygge sammen med.

BRUKERPERSPEKTIVET. Brukererens holdning om å ta pasientens perspektiver på alvor og tilretteleg-
ge for brukermedvirkning. Også brukerperspektivet er forankret $\mathrm{i}$ net. Hovedtemaen - Informasjon, både til og fra pasient//bruker og familien

BRUKERMEDVIRKNING. Brukermedvirkning er grunnleggende i rehabilitering. Medvirkning ne det gielder fär nodvendige god informasjon. Sykepleierne la vekt på betydningen av verdighet i denne sammenhengen. «Det er viktig for sykepleierne å være selvbestemmese. I aunnomiog sjonen er pasientens egne ressuravgjørende,, forklarte en av ning er itrád med etiske 
$\rightarrow \quad \begin{aligned} & \text { selvbestemmelse, og ligger til } \\ & \text { grunn for ivaretakelse av verdig- }\end{aligned}$ het under rehabiliteringen. B kermedvirkning er anerkjent som viktig for tilfredsstillende resul ter i rehabilitering (1

DOSERINGSPERSPEKTIVET. DOseringsperspektivet viser til hvordan sykepleiere vurderer grad, frekvens og tidspunkt samt varigheten og intensiteten for intervensjoner somiverksettes. Tiltakene «doseres》 utfore egenomsorg Doseringsperspektivet forholder seg dermed til unksjonstap, og er forankret i SMMs helse- og sykdomsdomene. Doseringsperspektivet var base valgende hovedten

Vurderinger av pasientens behov Terapeutisk til

Sykepleierne la vekt på observasjon og vurdering av pasientens tilstand. Deter av stor betydning at vi gir pate Vi giar vurderinger om når pasienten trenger hielp og når vi kan utfordre dem", kommenterte en sykepleier. Sykepleierne har ansvar for liv, helse og sikkerhet irehabiliteringen. Den terapeutiske tilnæretter hvert skal ivareta mest mulis av sin egenomsorg selv.

\section{MESTRINGSPERSPEKTIVET.} Mestringsperspektivet er basert pa pastentens rehabitteristmal ogat ler hun er fornoyd med. Mestringsperspektivet er grunnlagt i konsekvensene av skaden og funksjonsnedsettelsen og knyttes til helse- og sykdomsdomenet. Hotivet skal bidra til te selustendig liv - Egenaktivitet

- Læring

Empowermen

Mestringsperspektivet handler o opptrening og tilrettelegging. Målet nedelta på de arener mar âkunilivet. Â gjore selv og lære er viktis for mestringen. En av sykepleierne omtalte dette som sin hovedopp-

mellom å gi hjelp når det er nøđ bidra til at pasienten kermedvirkning og empowermen hjelper pasienten med å ta kontrol over sitt eget liv. La pasienten giore selv, bruke ADL - vasking, pakledfor å hjelpe pasienten til å oppnă selvkontroll.

Empowerment, i betydningen kunnskap og ressurser for å ta makten i eget liv, er en av rehabilhelt nødvendis for å mestre ese livssituasjon (15).

OMGIVELSER. Omgivelsesperspeltivet tar opp i seg de fysiske, sosiale og kutturelle variabler imiljøet pervet knytter seg derfor naturlig til SMM's omgivelsesdomene. Hovedtemaene er følgende

- Rehabiliterende omgivelse - Tverrfaglige samarbeid

Mens relasijng av livssituassionen der persondomenet omhandle sykepleierens perspektiv når de gielder relasjoner til pasient og $\mathrm{p}$ rorende, tar omgivelsesperspekt vet oppi segpersonens relasjoner i undersokelsen var mest oerne av pasientens umiddelbare omgivelser، «Det er viktig å fremme et godt milijø, ble det forklart. «Deltai sosiale aktiviteter i avdelingen dere, Rehabiliterande og savrundt personen er viktig for resultatene av rehabiliteringsprosessen (16). Tverrfaglig samarbeid, som er en del av omgivelsene, er av betyd ning for à oppna best mulig rehaet område der sykepleierne hadde ansvar for tilrettelegging og giennomføring i enheten.

I sine hjemmemiljøer og i hverdagslivet kan pasienten leve omgivelser som kan virke funkdeltakelse. Omgivelsene kan ogsa være funksjonsfremmende. Sykepleiere og andre som er engasje r rehabiliteringsfeltet og er opp- funksjonsnedsettelser, mả arbeide for å byggened funksjonshemmensøkelsen var opptatt av at pasienten skulle oppleve anerkjennelse og selv akseptere sin nye livssitunormalisering av situasjonen. Nor-

«Omgivelsene er

\section{viktig for resultatet}

\section{av rehabiliteringen.}

malisering av livssituasjonen vil for velser med fravær av funksjon-

\section{OVERSIKTSPERSPEKTIVET.} Oversiktsperspektivet innebærer sjonen på samfunns-, institusjonsog individnivå. Sykepleierne var særlig opptatt av à fả frem dette vet dreier seg om forhold som er av betydning for pasientens totale situasjon, som ofte ikke sees eller legges vekt på av andrei samarbei det. Derfor knytter også oversikts perspektivet seg til omgivelsesdoores kepleiernes mange oppgaver rehabiliteringsarbeidet

- Oversikt over og administrasjon av nødvendige oppgaver i enheten brukere over pasienten eller duelt nivå

sialisthelsetjeneste og andre instanser

Shlepleierne i en enhet har overselser og utskrivelser, den innlegpasients avtaler og kollegaers arbeidsoppgaver. De har et adminis trativt ansvar for at dagen skal fungere både for pasienter, pårørende det slik: «Jeg har blant annet en administrativ rolle. Jeg skriver rehabiliteringsplaner, rapporter gjennom dagen, ordner moter med rehabiliteringsteamet, tar kontakt med

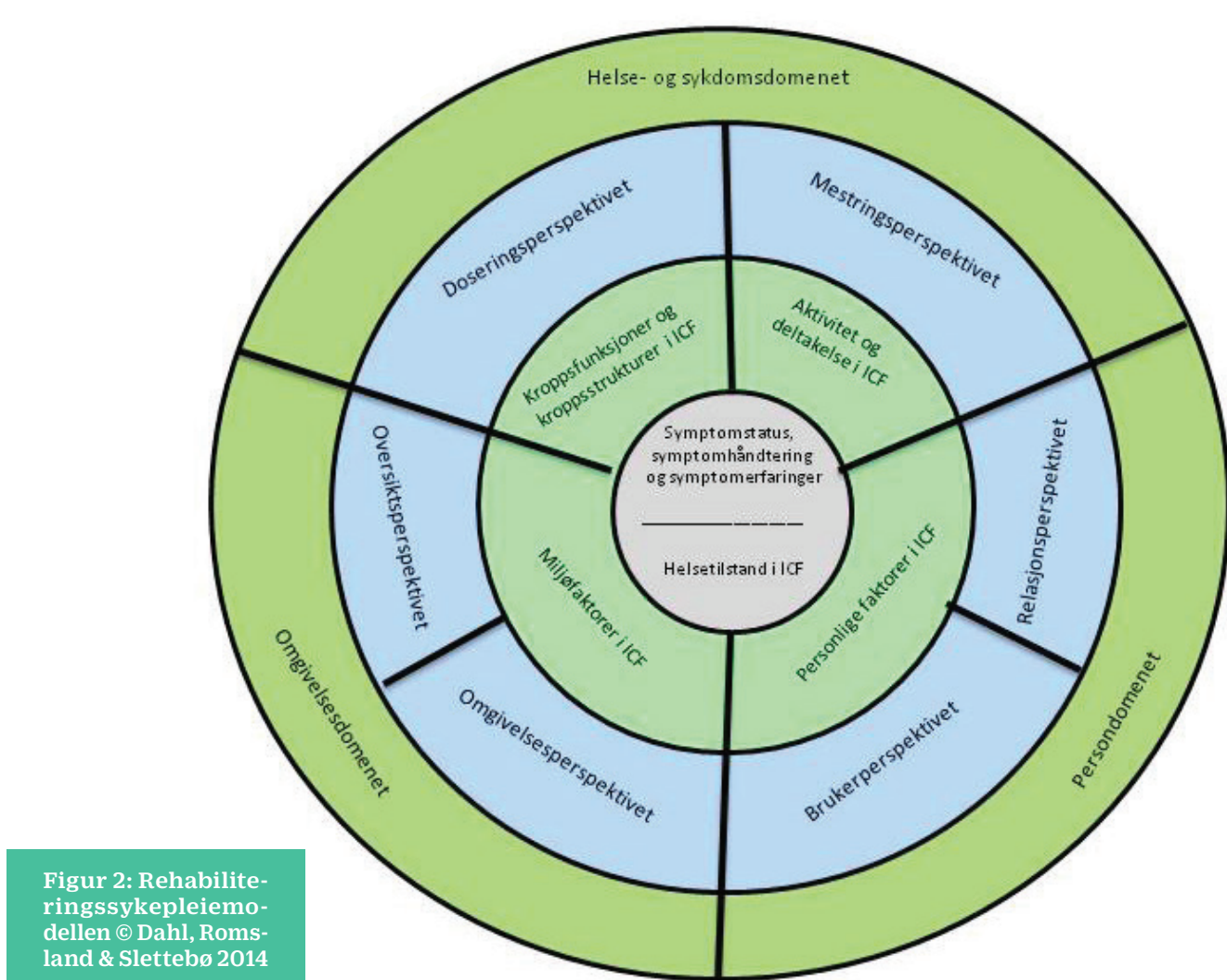

legger til rette for hjemreise.
Oversikten over pasiente r pasientenes tilntervensjoner ikke går utover paTentens behov Det kan for eksempel være at personen det gjelder ar vært til en slitsom treningsøokt hos fysioterapeut og trenger hvikepleierne beskrev også ansvare for samarbeid med andre instanser ved a de sorger for kontakter det er behov for utvikling av ruiner og virkemidler i framtidens helsetjeneste. Alt i alt bidrar sykepleierne til den flyten i hverdagslivet som har betydning for pasienomgivelser-

REHABILITERINGSSYKEPLEIEMODELL. De seks sykepleieper-

Sykepleien nr. 092014 perspektiver og sykepleiernes
forventete oppgaver i framtidens rehabiliteringstjenester.

AVSLUTNING. De seks perspektivene på rehabiliteringssykepleie syser sykepleiernesintervensioner i praktisk rehabiliteringsarbeid os bidrar til en beskrivelse av ansvarsområder og intervensjoner i irehabiliteringssykepleie. Ved å klargiøre sykepleieperspektivene i forhold res sykepleiens aktualitet i rehabliteringsarbeidet. Dette kan hijelpe sykepleiere med å strukturere os artikulere sine særegne ansvars-

REFERANSER:

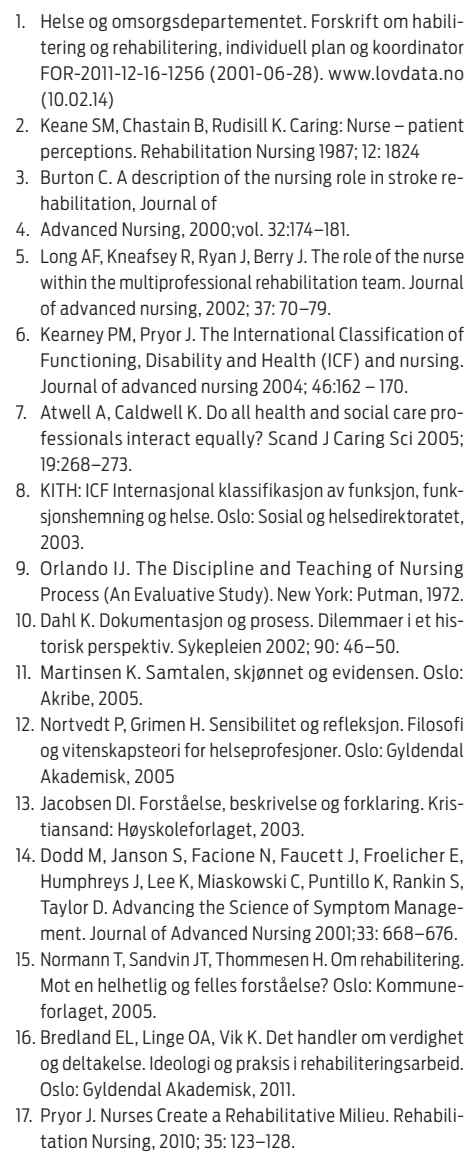

ICF-modellen (7). ICF består av helsedomener og helserelaterte donene i SMM (13). En forkkjell er nene i SMM (13). En forskjell er som forholder seg til domenene SMM, mens helsetilstand, som IC forstår som medisinske
er en egen faktor i ICF. Modellen for rehabiliteringssy sykephieperspetivene kan forsykepleiere som skal planlegge, utføre og rapportere sine vurderinger og intervensjoner innenfor ramringssamarbeid. Når sykepleiere ICF, kan de beskrve vurderinger, observasjoner os intervensjoner knyttet for eksem列erperspektivet, ut fra personfunksjoner og -strukturer kan det beskrives observasjoner, vurderinger og tiltak basert pà tilnæerMestringsperspektivet kan knyttes til ICF-faktorene aktivitet og deltakelse. Her kan sykepleiere deskive intervensjoner og vurderinger knyttet til egenaktivitet, ment. Ved å relatere omgivelsesperspektivet til ICFs omgivelsesfaktorer, kan sykepleiere beskrive eller rapportere når det gelder rysiske, holdaningsmesmidle samhe minivelser og forbeidet. Rehabiliteringssykepleipraksis på dette området, i tråd
FAGARTIKLER:

Fagartikler kan sendes til 